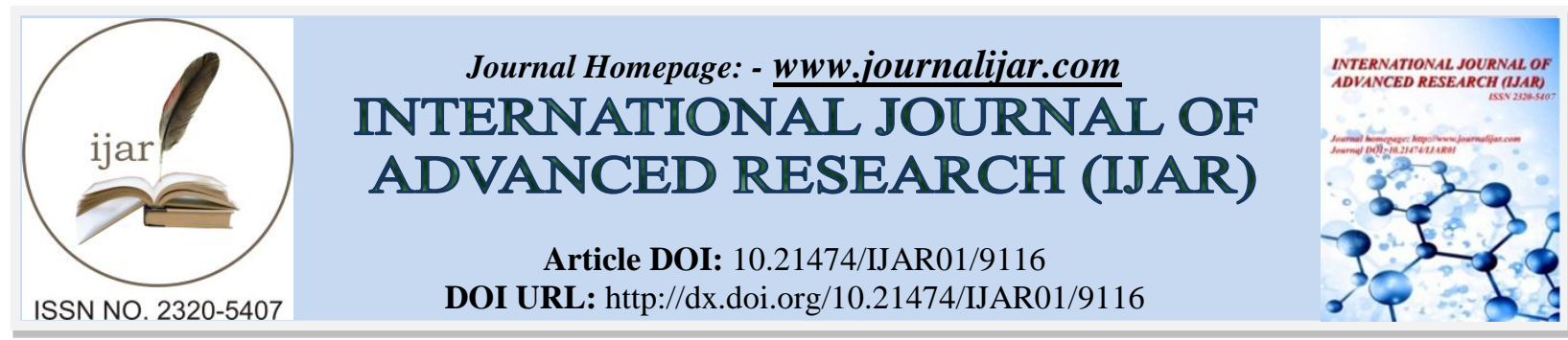

RESEARCH ARTICLE

\title{
MATERIAL SELECTION AND SOFTWARE SIMULATION OF DESIGNED PERMANENT MAGNET GENERATOR.
}

Yash R. Khakhi, Jashank A. Dighe, Harshil P. Thaker, Raj R. Patel.

Electrical Engineering Department, Gandhinagar Institute of Technology, Gandhinagar.

\section{Manuscript Info}

Manuscript History

Received: 22 March 2019

Final Accepted: 24 April 2019

Published: May 2019

\begin{abstract}
This paper presents a study on material used for the proposed design of Permanent Magnet Synchronous Machine (PMSM) and the 2D (Two Dimensional) analysis of Magnetostatics analysis for the designed model in software. It is more important to consider material selection and analysis for the accountancy of loss in the permanent magnet synchronous machines as they are having higher power output density. It is also necessary that an EM (Electromagnetic) field analysis accounting for the temperature rise throughout the machine should be taken into account because the heat generation from these loss transfers to the inside of the machine's structure causing changes in material properties, temperature rise in machine winding and finally an enormous impact on the machine characteristics.
\end{abstract}

Copy Right, IJAR, 2019,. All rights reserved.

\section{Introduction: -}

Material selection is one of the major factors while designing a rotating electrical machine. In the function of energy conservation material plays an important role as all the calculations of designing is done on the basis of properties of material selected. In order to gain high power density current Permanent Magnet Synchronous Machines (PMSM) work with a high flux in the airgap and therefore high flux densities in stator and rotor parts. Manufacturing process will also have effects on the final properties of the parts of the machines. During manufacturing the laminations are punched out of the coil to the desired shape. Attention has to be paid not only to the design but also on the manufacturing technique itself [1]. It is observed that manufacturing techniques such as laser cutting for prototyping or stamping during production will have the negative influence on the local magnetic properties of the material. This will result in iron loss depending on the manufacturing technique used. The different cutting methods will introduce mechanical stress in the material, resulting into locally decreasing magnetic permeability of magnet. On the other hand, it is also important that machine will have good mechanical and electrical properties which will make machine more efficient. Considering the losses due to manufacturing techniques and other losses such as iron loss, copper loss, stray loss and many more it is important to perform magnetic analysis of the machine for the acknowledgment of losses in the machine. During the development of rotating electrical machines. The major challenge is faced in the problem caused by the heat generation in the different parts of the machine, and it is not easy to specify and calculate the production of heat due to magnetic fields of magnetic material used in the machine. The thermal characteristic of IPMSM (interior permanent magnet synchronous machine) is very important as the generation of heat will affect the insulation of the winding, causing change in magnetic properties of magnet or demagnetizing of magnet. For the study of the effects 2D analysis of electromagnetic analysis is done in "MOTOR ANALYSIS - PM" and "MAGNET" software.I 


\section{Materials for The Proposed Design: -}

A. Structural Information

Our proposed designed PMSM will be a closed ends drum type structure made from nylon polymer and having permanent magnets on both stator and rotor. There will be a concentric winding for the generation of electromotive force. Other mechanical supporters like supporting members, bearings, conductor covers are also a part of structural design of machine.

B. Material Selection

As stated, earlier material selection is such type of process which will help to eliminate unnecessary losses resulting into increase in efficiency.

Selection of body material for the machine will have greater impact on iron losses of the machine because any metallic part of the machine will have greater or lesser contribution in iron loss of the machine. Nylon 66 is synthetic polymer called polyamides, with the numbers describing the type and quantity of polymer chains in their chemical structure [2]. Most nylons, including $6 \& 66$, are semi-crystalline. Nylon 66 should be used if a high performing engineering plastic is required that will be exposed to higher temperatures. Normally it is used in textile industry, friction bearings, radiator caps and tire ropes because of its advantages.

Properties of Nylon-6 material is sown in table 1 which suggest the it can be use in proper manner for the body material of the machine.

\begin{tabular}{|c|c|}
\hline Mechanical Strength & High \\
\hline Wear Resistance & High \\
\hline Electrical insulating Property & Good \\
\hline Temperature Resistance & High \\
\hline
\end{tabular}

Table 1 - Properties of Nylon 6

Generation of proper magnetic field is the major factor affecting the performance of any PMSM [4]. Use of rare earth magnets will give higher magnetic field than using electromagnets. And also, rare earth magnets will have longer life span. Table 2 shows the main magnetic characteristics of different rare earth magnets [7] for the selection of proper magnets for the working of machine. It is seen that Neodymium magnets have the best magnetic characteristics among all other magnets.

\begin{tabular}{|c|c|c|}
\hline Magnet & Remanance $(\mathrm{T})$ & $\begin{array}{c}\text { Coercivity } \\
(\mathrm{kA} / \mathrm{m})\end{array}$ \\
\hline Alnico & 0.6 & 0.07 \\
\hline $\mathrm{MnBi}$ & 0.48 & 0.37 \\
\hline SmCo & 0.83 & 1.0 \\
\hline Neodymium & 1.2 & 1.2 \\
\hline
\end{tabular}

Table 2 - Properties of rare earth magnets

Crystal structure of the neodymium magnet is composed of microcrystalline grains that are aligned in a powerful magnetic field during manufacture so their magnetic axes all point in the same direction. The crystal lattice of the magnet resists to turning its direction of magnetization which makes this compound highly coercive to demagnetize.

\begin{tabular}{|c|c|}
\hline Property & Neodymium \\
\hline Remanence $(\mathrm{T})$ & $1-1.3$ \\
\hline Relative permeability $\left(\mu_{\mathrm{r}}\right)$ & 1.05 \\
\hline Coercivity $(\mathrm{MA} / \mathrm{m})$ & $0.875-1.99$ \\
\hline
\end{tabular}

Table 3 - Properties of Neodymium magnet

Fig. 1 depicts the values of remanence and coercivity of the neodymium magnet over its entire working temperature range. The working temperature range for $\mathrm{NdFeB}$ is from $-40^{\circ} \mathrm{C}$ to $100^{\circ} \mathrm{C}$. It can work intrinsically at very lower temperature and can work normally at very higher temperature. Due to its wide working temperature range it is more preferred over other magnets for the higher magnetization though they are little bit costly from other rare earth magnets. 


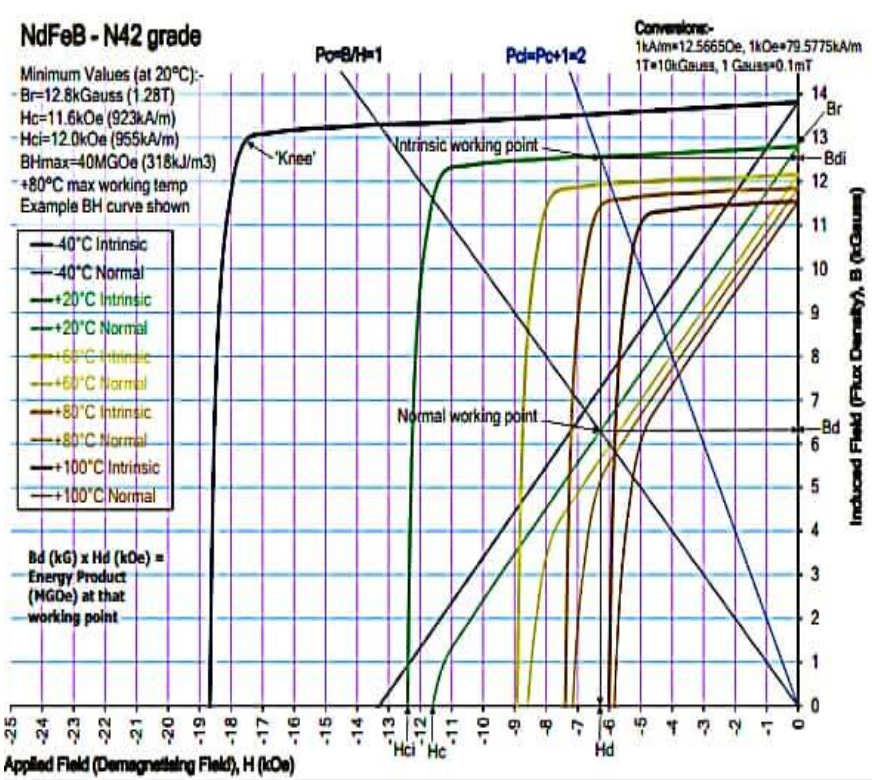

Fig - 1. Magnet BH curve

\section{Analysis Model:-}

C. Specification of Analysis model

Table 4 shows the specifications of $1 \mathrm{~kW}$ interior PMSM [6].

\begin{tabular}{|c|c|c|c|}
\hline & Item & Unit & Specification \\
\hline Rated & Current & $\mathrm{A}$ & 2.9 \\
\hline & Power & $\mathrm{kW}$ & 1 \\
\hline & Speed & $\mathrm{Rpm}$ & 1500 \\
\hline Stator & No. of Slots & & 48 \\
\hline & O.D & $\mathrm{mm}$ & 223 \\
\hline & I.D & $\mathrm{mm}$ & 83 \\
\hline & Tooth width & $\mathrm{mm}$ & 4.3 \\
\hline Rotor & Poles & & 4 \\
\hline & Diameter & $\mathrm{mm}$ & 80 \\
\hline & Axial length & $\mathrm{mm}$ & 192 \\
\hline
\end{tabular}

Table 4 - Analysis Specifications

The 2D model shown in fig. 2 depicts the real geometry of the interior PMSM which is having shaft, rotor, permanent magnets, stator core. And in fig 3, fig 4 and fig 5 for magnetostatic analysis showing magnetic flux density, magnetic field intensity and mesh analysis model respectively [8]. 


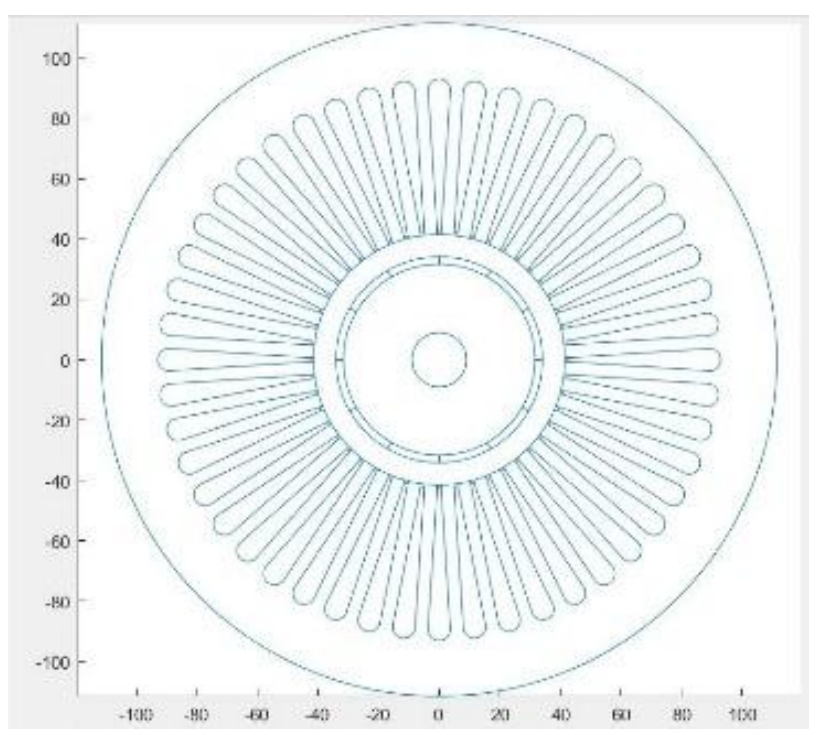

Fig 2 - Geometrical model

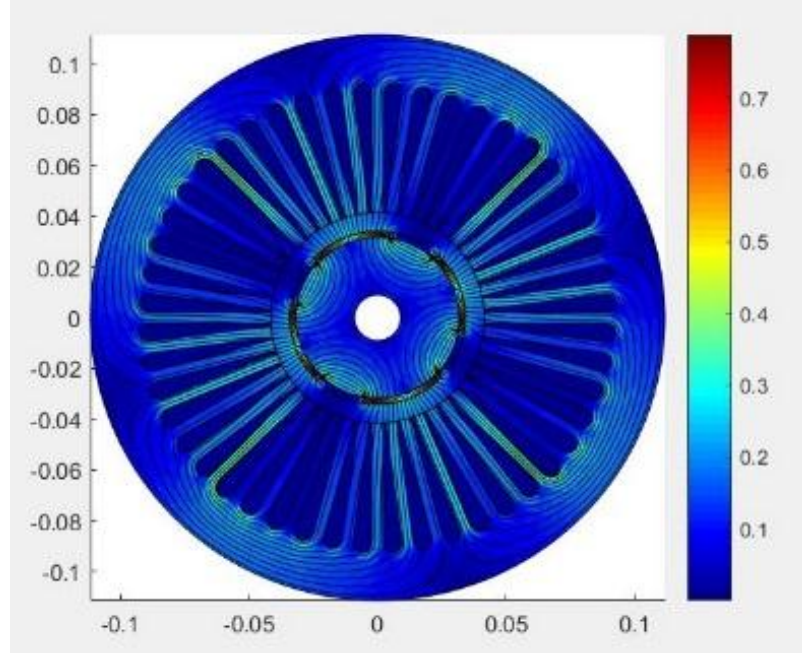

Fig. 3 - Magnetic flux density

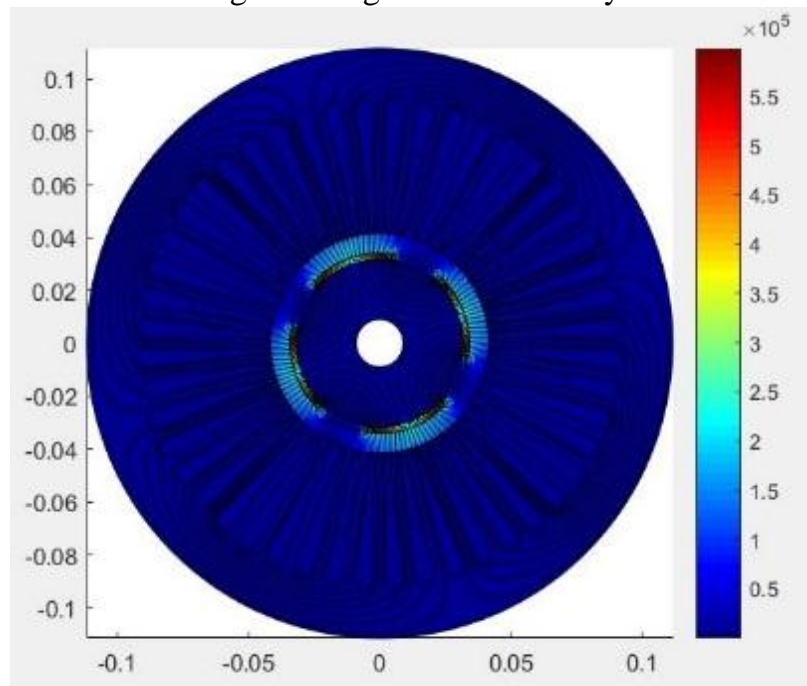

Fig. 4 - Magnetic field intensity 


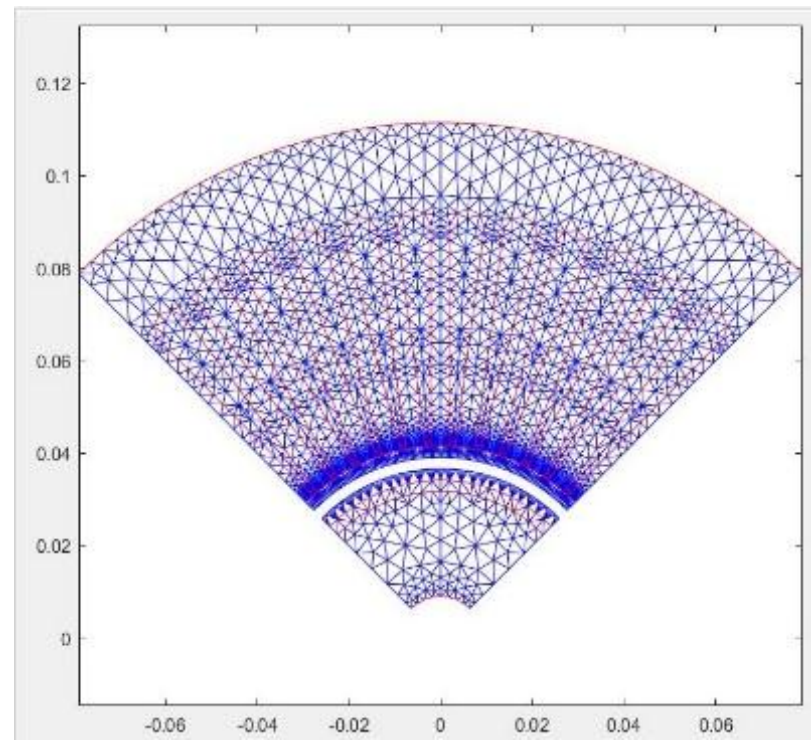

Fig. 5 - Mesh analysis model (1/8)

D. Analysis Procedure

Fig 6 illustrate the flow chart of the proposed magnetic analysis procedure.

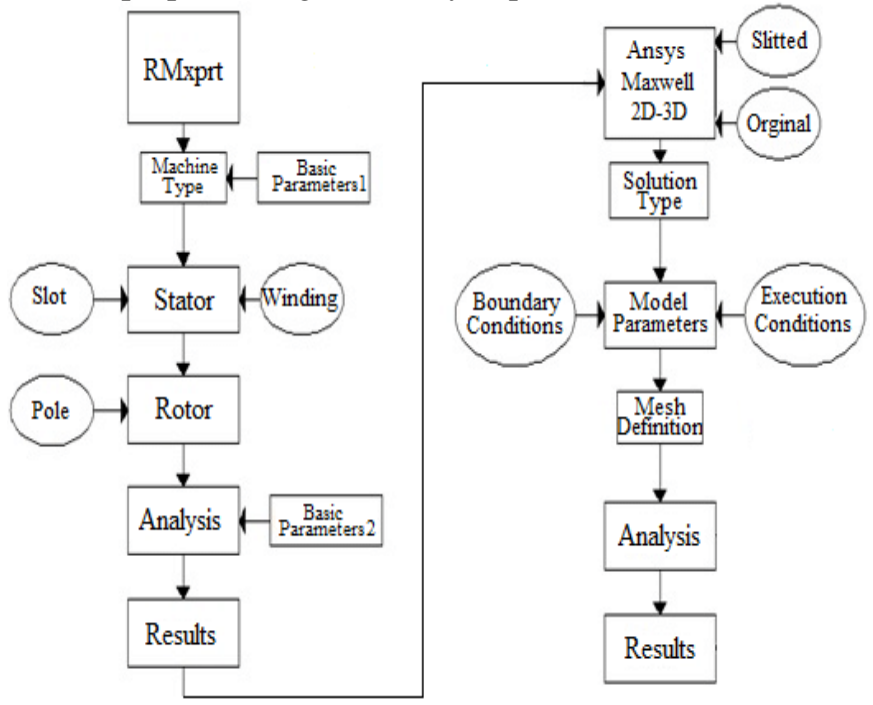

Fig. 6 - FEA analysis flow chart

\section{E. Magnetostatic Analysis}

Maxwell's equations are used to get the magnetic phenomena in the machine. Overall, the motor characteristics in 2D and 3D analyses are very similar, ignoring some differences such as the leakage flux occurred in end-windings and slot leakage reactance which depends on the winding shape in the slot. However, the copper loss in the coils and iron loss in the core are the main heat sources. Flux passing through axial axis of the machine and current flowing through end winding must be considered in order to measure losses [3].

Generation of heat due to passing of current in winding coils having resistance R can be expressed by using joule's heat loss equation:

$$
W_{\text {copper }}=I^{2} \times R
$$

Thus, heat generated is directly proportional to the square of current passing through the winding and resistance divergent increases with increase in temperature.

Iron loss (hysteresis loss) in the machine can be expressed by steinmetz equation:

$$
W_{h}=B_{\max }^{1.6} f V
$$

Where $\mathrm{f}$ is the frequency of flux reversal and $\mathrm{V}$ is the volume of core of the machine. 
Calculation of Copper and Iron losses in the machine can be calculated by the $2 \mathrm{D}$ analysis. The results for the selected 35 grade neodymium magnet are shown here in table 5.

\begin{tabular}{|c|c|c|}
\hline Type of Loss & Unit & Value \\
\hline Stator Winding loss & W & 2.088 \\
\hline Total Iron loss & W & 2.727 \\
\hline Eddy current loss & W & 0.194 \\
\hline Hysteresis iron loss & W & 2.533 \\
\hline Magnet eddy current loss & W & 0.006 \\
\hline
\end{tabular}

Table 5 - Losses for $1 \mathrm{~kW}$ proposed machine

Comparison of different graded magnetic material having different magnetic losses is shown in figure 7 which gives conclusion that our selected magnet will give the least loss full operation.

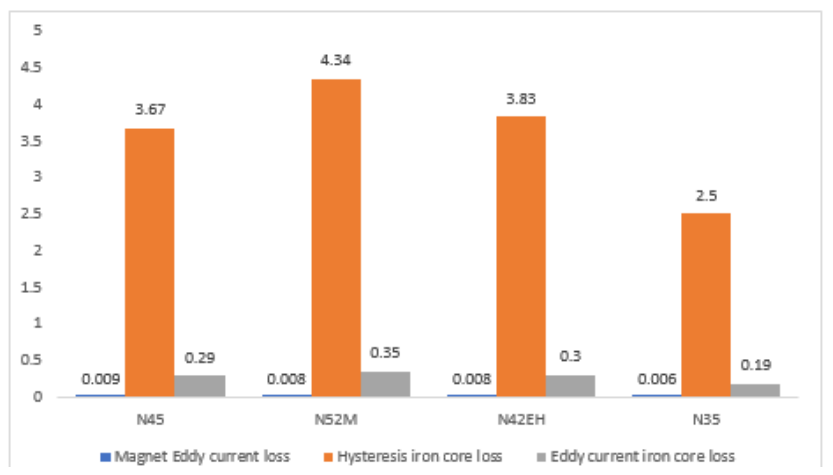

Fig. 7 - Comparison of different losses

\section{SIMULATION RESULT:-}

2D magnetostatic analysis was performed in motor analysis - PM software. Flux density distribution is already displayed in fig. 3. To calculate the losses more accurately current and voltage values [5] are displayed in fig. 7 and the value of flux density is showed here in fig. 8.

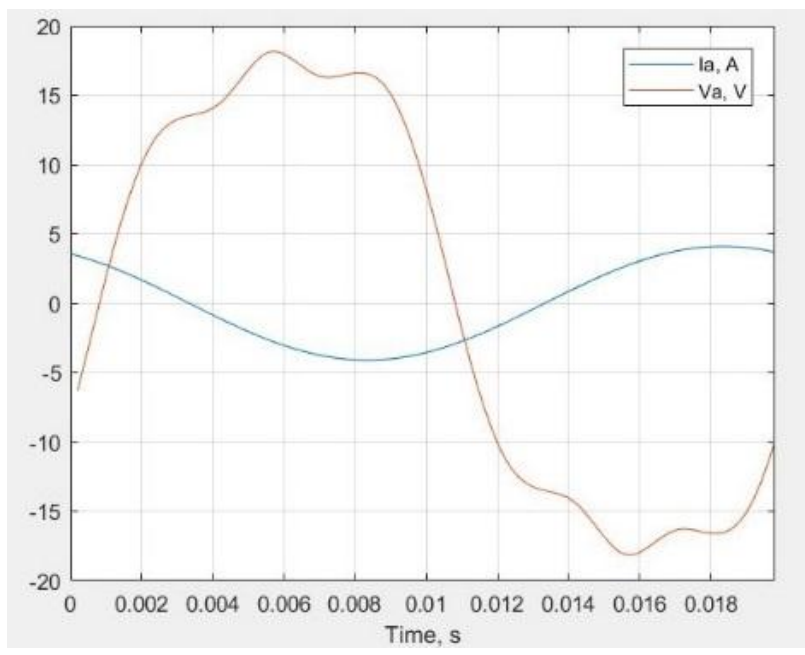

Fig. 8 - Current and Voltage wave form 


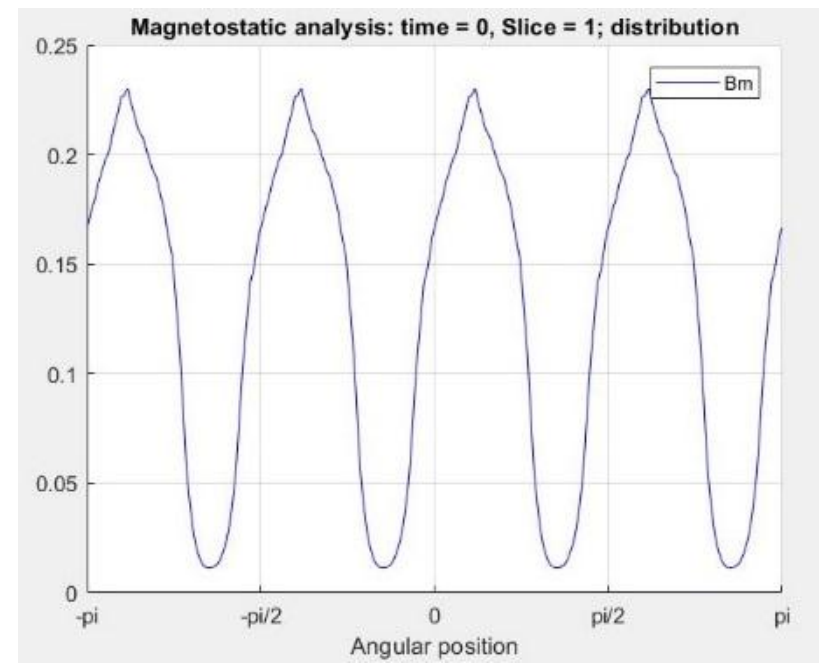

Fig. 9 - Flux density waveform

\section{Conclusion:-}

This paper gives the detailed study on material selection for the PMSM and gives its magnetostatic analysis for the different loss calculation. It is proposed that nylon type polymer material can be used for the small rated machine as it is having all required qualities and can eliminate the major iron losses. High graded rare earth magnetic material can be used to achieve high power density in machine. This proposed model is under designing stage and further detailed study and improvement in material selection and magnets can be led to more and more efficient machine.

\section{Acknowledgment: -}

The authors would like to acknowledge the project guide for providing their support and guidance for the ansys of the proposed model.

\section{References:-}

1. IEEE paper on Influences of material degradation due to laser cutting on the operating behavior of PMSM using a continuous local material model by Silas Elfgen, Simon Steentjes, Stefan B"ohmer, David Franck, and Kay Hameyer.

2. IJSR published paper on chemistry, properties and uses of nylon by Parth Vagholkar.

3. IEEE published paper on Electromagnetic-Thermal Coupled Analysis Method for Interior PMSM by Jae-Bum Park, Morteza Moosavi, Hamid A. Toliyat.

4. Oleg Lyan and Vincent Monet, Final Thesis on "Research of permanent magnet generator with compensated reactance winding".

5. IEEE paper on Design, Fabrication and Analytical Investigations on a Permanent Magnet Synchronous Generator by Subhrakanti Nanda, Mainak Sengupta.

6. S. Paitandi And M. Sengupta, Design, analysis of a PMSM and its comparative study With an Induction Machine of same nominal rating, NPEC, December 2013, IIT Kanpur.

7. Article on Influence of Magnet Material Selection on the Design of Slow-Speed Permanent Magnet Synchronous Generators for Wind Applications in Elektronika ir Elektrotechnika by Ants Kallaste, Toomas Vaimann and Anouar Belahcen.

8. Paper on Optimum Design of a Three-Phase Permanent Magnet Synchronous Motor for industrial applications in International Journal of Applied Operational Research by M.J. Soleimani Keshayeh and S. Asghar Gholamian. 